\title{
The Influence of Types of Stimulation and Attitudes to Clitoral Self-stimulation on Female Sexual and Orgasm Satisfaction: a Cross-sectional Study
}

\author{
Madita Hoy $^{1}$ D $\cdot$ Katharina van Stein ${ }^{1} \cdot$ Bernhard Strauss $^{1} \cdot$ Katja Brenk-Franz $^{1}$
}

Accepted: 5 July 2021 / Published online: 21 July 2021

(c) The Author(s) 2021

\begin{abstract}
Introduction Societal assumptions and individual myths that define vaginal penetration as normal sexuality can affect the sexual pleasure of varied sexual activities. Although women orgasm much more easily through direct clitoral stimulation than through vaginal intercourse, many couples desire the latter. The purpose of this study is to investigate how orgasms from different types of stimulation with a partner affect sexual satisfaction and orgasm satisfaction in cisgender women. Also, the attitude of women to stimulate their clitoris themselves to reach orgasm during sex with their partner will be included. Methods Two independent surveys $(\mathrm{N}=388$ and $\mathrm{N}=555)$ were conducted online in 2016 and 2020.

Results Regression analyses showed that orgasm consistency through sexual intercourse had a stronger influence on orgasm satisfaction and sexual satisfaction than orgasm consistency through oral sex, stimulation by the partner's hand, or selfstimulation. Positive thoughts and feelings about self-stimulation of the clitoris during sex with the partner showed only little effect, but in some cases, they were even negatively related to the reported satisfaction.

Conclusions The results indicate that the common misconception about sexuality, that it is normal for women to experience orgasms during penile-vaginal intercourse, influences the subjective evaluation of one's own sexuality. Orgasms from clitoral stimulation seem to have a second-class quality for some women, although there is no evidence that these orgasms feel like less pleasureable.

Policy Implication Rigid assumptions about what normal sexuality should look like should be publicly addressed and discussed in sex education classes.
\end{abstract}

Keywords Female orgasm $\cdot$ Clitoral stimulation $\cdot$ Intercourse $\cdot$ Self-stimulation $\cdot$ Oral sex

\section{Introduction}

The female orgasm is a complex experience with emotional, mental, and physical components (Bentler \& Peeler, 1979). The variability of orgasmic experience ranges widely, following that the description of a typical pattern of female orgasm may oversimplify the phenomenon (Mah \& Binik, 2001). In addition to different sensations, subjective evaluations and the significance of one's own orgasm can also vary significantly. Therefore, personal,

Madita Hoy

madita.hoy@med.uni-jena.de

Institute of Psychosocial Medicine, Psychotherapy and Psycho-Oncology, Jena University Hospital, Jena, Germany interpersonal, and sociocultural factors can be relevant (Séguin \& Blais, 2019). Often, the orgasm is seen as a goal of sexual activity (Lavie-Ajayi \& Joffe, 2009). Messages about the importance of orgasm can cause distress and pressure to perform (Graham, 2010). Accordingly, the subjective needs and feeling of sexual satisfaction should be the focus rather than social norms about sexuality. For this reason, this work focuses on sexual satisfaction and orgasm satisfaction in dependence from orgasm consistencies from different types of stimulation as well as attitudes toward clitoral self-stimulation during partnered sexual encounters.

The female orgasm can be important for the sexual satisfaction of women (Leonhardt et al., 2018). For example, sexually satisfied women in long-term relationships reported a higher orgasm consistency (78\%) than sexually unsatisfied women $(41 \%)$, with the length of relationship having 
an increasing effect on orgasm consistency (Frederick et al., 2017). For most women, satisfaction with sex life is more related to sexual intercourse than to masturbation or petting (Philippsohn \& Hartmann, 2009). Nevertheless, in average, women reported vaginal penetration as less satisfying than men, unless clitoral stimulation is included (Blair et al., 2017). However, while for some women orgasm is a key factor for sexual satisfaction, for others, emotional aspects, such as emotional closeness to a partner or feeling safe, may be more relevant (McClelland, 2014). Although there is a substantial overlap between the constructs, sexual satisfaction is more than satisfaction with intercourse or satisfaction with orgasms. It includes personal experiences and sensations, partner's behaviors, and sexual activity in general (Stulhofer et al., 2010). Therefore, sexual satisfaction can also be high without experiencing orgasms (Philippsohn \& Hartmann, 2009) or even without sexual activity (Matthias et al., 1997).

Whether women experience orgasms depends mainly on the type of sexual activity (Andrejek \& Fetner, 2019). Direct stimulation of the clitoris improves the regularity of experienced orgasms, called orgasm consistency and orgasm quality (Herbenick et al., 2018). During sexual intercourse without direct clitoral stimulation, only about one-third of all females experience an orgasm (Prause et al., 2016). In contrast, during masturbation, 59\% of women usually experienced an orgasm (Dunn et al., 2005). Approximately $14 \%$ of female participants have never had an orgasm or are unsure if they had one (Dunn et al., 2005; Prause et al., 2016). Moreover, there is a negative trend for young women (under the age of 35) to experience orgasms during intercourse. Large representative surveys from Finland showed that in $1999,53 \%$ of the women reported regularly achieving orgasm during penile vaginal intercourse (PVI). In 2007, this number decreased to $42 \%$ and in 2015 to $38 \%$ (Kontula \& Miettinen, 2016). Whether direct clitoral stimulation was used during PVI was not differentiated.

When women report orgasm difficulties, they usually mean that they cannot reach orgasm during intercourse (Lavie-Ajayi \& Joffe, 2009). There have been myths about the difference between clitoral and vaginal orgasm for a long time. For example, it is a common misconception that it is normal for women to orgasm during sexual intercourse without clitoral stimulation (Ejder Apay et al., 2013). Discussions distinguishing between vaginal and clitoral orgasms are also common in media, such as women's magazines (Lavie-Ajayi \& Joffe, 2009). There are deeply internalized assumptions that penile-vaginal intercourse is the normal, natural way to have sex and therefore women should experience orgasms in this way (Jackson, 1984). Female orgasms can be created by different types of stimulation, but the distinction between vaginal and clitoral orgasms is outdated: The clitoris consists not only of the visible clitoris glans, but also of the clitoris bulbs next to the vaginal walls. Erectile tissue stretches into the vaginal opening and overlaps with other areas of heightened sexual responsiveness such as the G-spot (Blechner, 2017; O'connell et al., 2008). There is no clarity if the G-spot is an anatomically distinct area (Blechner, 2017). While approximately half of all women report to have a G-spot, there are no hints for genetical factors for the self-reporting of the presence of this area (Burri et al., 2009).

So, during vaginal penetration, underlying parts of the clitoris are stimulated. Most women report that they use clitoral and vaginal stimulation to experience orgasm (Prause et al., 2016). The subjective perception of an orgasm can differ depending on whether an orgasm is reached by vaginal or clitoral stimulation. Most women distinguish between types of stimulation rather than based on qualitative sensations (Lehmann et al., 2004). Whether orgasms from vaginal penetration or clitoral stimulation feel better may vary between women. In a large twin study analyzing influences of self-reported aspects of the G-spot, it was found that even when women reported having a G-spot and experienced orgasms from vaginal penetration, many women preferred orgasms from clitoral stimulation based on quality of sensations (Burri et al., 2009). Other studies showed no reported differences in the quality of orgasms from vaginal and clitoral stimulation (Lehmann et al., 2004; Prause et al., 2016). However, orgasms through vaginal penetration are stronger correlated with partnered sexual satisfaction (Lehmann et al., 2004). In contrast, orgasm consistency through clitoral stimulation is related to more sexual desire and higher sexual arousal (Prause et al., 2016). Unrelated to the type of stimulation, women who orgasm more frequently reported a higher awareness of their bodily sensations, more erotic fantasies during intercourse, more variation in their sexual behavior (de Sutter et al., 2014), and higher emotional intimacy (Mah \& Binik, 2005). Many women who have difficulties experiencing an orgasm report psychological strain and low satisfaction with their sexual relationship (Rowland $\&$ Kolba, 2016). A low orgasm frequency is related to cognitive distraction, e.g., automatic thoughts (Tavares et al., 2017), suppression of erotic thoughts, pressure to perform (Cuntim \& Nobre, 2011), and sexual myths (Philippsohn et al., 2003).

The presence of sexual myths and sexual pressure to perform indicates a strong expectation to experience orgasms during sexual intercourse. Mainstream pornographic videos support this, showing female orgasm most commonly through penetration without additional clitoral stimulation (Séguin et al., 2018). Romantic novels promote a picture of women, who orgasm fast and high frequently, which can feed unrealistic expectations about one's own sexuality (Cabrera \& Ménard, 2013). Traditional sex roles, like female passivity and male agency, are also promoted in these novels (Cabrera \& Ménard, 2013). Factors like these can cause 
heteronormative scripts, which place sexual intercourse in the center of sexuality. These can hinder women's orgasm, because women are more likely to orgasm if the sexual behavior is diversified (Willis et al., 2018). Women in samesex relationships reported a higher orgasm frequency and satisfaction from partnered clitoral stimulation than women in mixed-sex relationships (Blair et al., 2017).

\section{Current Study}

The fact that the orgasmic consistency of women is strongly dependent on the type of stimulation was shown in several studies. This study is more focused on the subjective perception of orgasms and aims to investigate how sexual satisfaction is related to orgasms created by different types of stimulation. Sexual and orgasm satisfaction should be more important than the mere frequency of orgasms or sexual intercourse. Which factors are decisive for women in this respect were rarely investigated. Also, this study aims to find out how personal responsibility for one's own orgasm affects satisfaction. Therefore, self-stimulation during sexual encounters will also be investigated. While masturbation in women can enhance a sense of sexual empowerment, meaning to feel strong, sexy, independent, and satisfied (Bowman, 2014), there is no evidence yet of how self-stimulation during sex with a partner affects sexual satisfaction. A better understanding of factors that influence satisfaction can be helpful in sexual counseling to develop strategies with clients that promote a pleasurable sexuality.

The subjective importance women connect with the experience of orgasms seems to be influenced by many factors. The current study will investigate whether orgasms by several types of stimulation in partnered sexuality (PVI, PVI and direct clitoral stimulation, stimulation by the partner's hand, oral sex, and self-stimulation of the clitoris during sex with a partner) are particularly relevant for sexual satisfaction and orgasm satisfaction. In addition, cognitive and affective aspects of clitoral self-stimulation should be emphasized. Furthermore, a distinction should be made between orgasm satisfaction and the broader construct of sexual satisfaction. By focusing on the experience of orgasm through vaginal and clitoral stimulation, this study is related to the sensations of cisgender women with heterosexual experiences including PVI. In addition, the study will be run in a second, independent sample to validate the results.

In summary, the following questions can be derived:

To what extent are orgasmic satisfaction and sexual satisfaction influenced by orgasmic consistency across different types of stimulation (PVI, PVI and direct clitoral stimulation, stimulation by the partner's hand, oral sex and selfstimulation of the clitoris during sex with a partner)?
To what extent are orgasmic satisfaction and sexual satisfaction influenced by affective and cognitive attitudes toward self-stimulation of the clitoris during sex with a partner?

\section{Methods}

We performed two cross-sectional online surveys in Germany via SoSciSurvey.com (Leiner, 2014). The platform offers high data privacy standards, providing optimal protection of the privacy of our proband. Data for sample 1 were collected from Aug 2016 to Oct 2016. Four hundred twelve cisgender women completed the survey. Some women were excluded from analyses because they had never had sex with a partner. Also, datasets were scanned for meaningless data, those created very fast, straight, or weird. For this purpose, SoSciSurvey provides the relative speed index (RSI), and we excluded datasets with a RSI with a value of 2.0 and above (Leiner, 2019). Since all questions had to be answered, there was no missing data. The final sample included 388 cisgender women. Data of sample two were collected from Aug 2020 to Sept 2020. The second survey was completed by 574 women. The same exclusion criteria as in the first survey were applied. Five hundred fifty-five cisgender women were included in the analyses.

The links to the anonymous studies were shared online. They were spread via internet forums, student mailing lists, and by snowballing methods. No financial incentive was provided. Criteria for inclusion in the studies were being at least 18 years old and identifying oneself as a cisgender woman. Exclusion criteria were insufficient German language skills and the lack of informed consent. The studies received ethical approval from the Ethics Committee of the University Hospital Jena, and we agree with the terms of good clinical practice and the declaration of Helsinki.

\section{Measurements}

Sociodemographic variables were collected, including age, sex, education, sexual orientation, and relationship. Participants were also asked about the frequency of sexual activities, like masturbation, and partnered sexual activities.

\section{NSSS}

The New Sexual Satisfaction Scale (NSSS) (Stulhofer et al., 2010) is an internationally established questionnaire for assessing sexual satisfaction. The short version, which was used in this study, comprises 12 items. The NSSS covers different dimensions of sexual satisfaction. These include individual aspects such as factors of sexual function and partner-related aspects like partner creativity. The internal 
consistency for the German version is excellent $(\alpha=0.96)$ (Hoy et al., 2019). Internal consistency in the study samples was $\alpha=0.92$ in sample 1 and $\alpha=0.96$ in sample 2 . All items were recorded on a five-point Likert scale ranging from 1 (not satisfied at all) to 5 (very satisfied). Higher scores reflected higher satisfaction with one's sex life.

\section{FOS}

The Female Orgasm Scale (FOS) (McIntyre-Smith \& Fisher, 2011b) assesses the consistency of orgasm depending on different types of stimulation (PVI, PVI and direct clitoral stimulation, stimulation by the partner's hand, oral sex, and self-stimulation of the clitoris during sex with a partner), as well as satisfaction with frequency and quality of orgasms. Five items assess how often an orgasm is reached during specific sexual activities (e.g. "How often do you have an orgasm from vaginal penetration only (no direct clitoral stimulation) during intercourse with a partner? Please indicate what percentage of the time on a $0-100 \%$ scale"). A rating is applied in $10 \%$ steps, so the results are between 0 and 10 . There is one additional option per item that allows participants to indicate that no such activity was experienced. The authors suggest, depending on the focus of the research question, to count this category either as missing or as zero (no orgasms by this type of stimulation). For the presented analyses, the second option was chosen because the openness towards different types of stimulation was also of interest, and this is also expressed at the behavioral level. Two additional items were included to measure satisfaction with frequency and quality of orgasms on a 7-point scale ranging from very satisfied to very unsatisfied. The original FOS was generated across three studies using different samples and choosing items with the best psychometric properties, resulting in good reliability and validity. Internal consistency was good in all three studies for the total scale $(\alpha=0.84-0.86)$ and both subscales "Orgasm from Clitoral Stimulation" $(\alpha=0.81-0.82)$ and "Satisfaction with Orgasm" ( $\alpha=0.72-0.90)$ (McIntyre-Smith \& Fisher, 2011b). "Orgasms from Vaginal Penetration" was only assessed by a single item. Since the aim of the study is to focus on specific types of stimulation, single items were also used to assess orgasm consistency through different types of clitoral stimulation. Internal consistency for "Satisfaction with Orgasm" in the study samples were $\alpha=0.88$ in sample 1 and $\alpha=0.89$ in sample 2 .

\section{CSSS}

The Clitoral Self-Stimulation Scale (CSSS) assesses behavior, attitudes, and affects concerning clitoral selfstimulation during sexual intercourse with a partner. The scale includes six items (McIntyre-Smith \& Fisher, 2011a).
The psychometric properties were mostly good: Internal consistency of the total scale was good $(\alpha=0.82-0.86)$, but there were mixed results for the subscales $(\alpha=0.59-0.86)$. Also, the German version of the CSSS showed inconsistencies within the subscales. Therefore, we refer to single items. Three positive poled items of the scale were included in the analyses. Two items of the subscale "Attitudes Towards Clitoral Self-Stimulation" (e.g., "Stimulating myself (i.e., massaging my genitals/clitoris) to help me have an orgasm during intercourse with a partner would be: important" or "good"). One item of the subscale "Affective Reactions to Clitoral Self-Stimulation" (e.g., "Stimulating myself (i.e., massaging my genitals/ clitoris) to help me have an orgasm during intercourse with a partner would be: exciting") was included. Other items were not included because of ceiling effects in the data or redundance with the FOS.

\section{Statistical Analysis}

All analyses were conducted using IBM SPSS (version 23.0) for Windows. The samples were analyzed for differences in sociodemographic variables using T-tests for independent samples. Multiple linear regressions were assessed to predict orgasm satisfaction and sexual satisfaction. The assumptions for regression were tested, using the variance inflation factors (VIFs), Durbin-Watson statistic, histograms, and residual-vs-fitted diagrams. The results confirmed that the variables were suitable for regression analysis.

All regression models were tested in both samples. The same predictors were included in each model. This involved orgasmic consistency by different types of stimulation (PVI, PVI and direct clitoral stimulation, stimulation by the partner's hand, oral sex and self-stimulation of the clitoris during sex with a partner). In addition, positive attitudes and affections toward clitoral self-stimulation during partnered sexuality were included as predictors in the model, indicating whether it was perceived as good, important, and exciting. Age and relationship status were included as control variables. The models were calculated in two independent samples. Moreover, we used a hierarchical approach to investigate which predictors might be responsible for shared variance. In a first step, regressions were calculated with the control variables, and in a second step, the attitudes toward clitoral self-stimulation were added. Additionally, a crossvalidation of the model from sample one was performed on the second sample. Therefore, the regression coefficients from sample 1 were used to predict orgasm satisfaction and sexual satisfaction in sample 2 . The explanation of the variance of the predicted values in relation to the true values was verified by regression analysis. For all analyses, the alpha error threshold was set to $5 \%$. 


\section{Results}

\section{Participant Characteristics}

The first sample consisted of 388 women ranging in age between 18 and $58(M=27.48, S D=8.02)$. Approximately half of the participants indicated to be currently in a relationship. The level of education was high with 93\% $(N=361)$ having achieved A-levels or specialized A-levels, which corresponds to a school education of at least 12 years.

The second sample consisted of 555 women ranging in age between 18 and $60(M=25.46, S D=6.12)$. A total of $71.7 \%(N=398)$ were in a relationship. A total of $91.7 \%$ $(N=509)$ of the participants had a high level of education.

The orgasmic consistency for vaginal penetration was 2.6 in study 1 and 2.5 in study 2 , meaning that women experienced orgasm on average approximately $25 \%$ of the time. The number of orgasms caused by clitoral stimulation was more than twice as likely. A total of $40.2 \%$ $(N=156)$ in sample 1 and $40.0 \%(N=222)$ in sample 2 never achieved orgasm through penetration without direct clitoral stimulation. For clitoral stimulation in sample 1 $8.2 \%(N=32)$ and in sample $24 \%(N=22)$ of the women reported to never reach orgasm. Further sample descriptions can be found in Table 1 .

The samples differ with respect to some sociodemographic factors. The first sample was older $(\mathrm{t}(941)=4.40$, $\mathrm{p}<0.01)$ and the second sample had more women in partnerships $(\mathrm{t}(941)=-5.97, \mathrm{p}<0.01)$. There were no significant differences in sexual orientation $(\mathrm{t}(941)=0.43, \mathrm{p}=0.67)$.

\section{Predictors of Satisfaction with Orgasms}

A multiple regression was run to predict satisfaction with orgasm from orgasm consistency via different stimulation types and attitude and emotion toward clitoral selfstimulation during partnered sexuality. The multiple linear regression model (Table 2) explains $30.2 \%$ of the variance of the variable orgasm satisfaction in sample 1 and $35.4 \%$ in sample 2. Orgasmic consistency by PVI, PVI and direct clitoral stimulation, and stimulation by the partner's hand indicated orgasm satisfaction in both samples. Self-stimulation of the clitoris during sex with a partner was only a significant predictor in sample 1 . Orgasmic consistency due to oral sex was not a significant predictor. A negative predictor was to consider clitoral stimulation during sex as important. There was no significant effect of perceiving self-stimulation as good or exciting.

Additionally, we tested hierarchical effects. Therefore, one regression was run with age and relationship status as
Table 1 Characteristics of the study samples

\begin{tabular}{|c|c|c|}
\hline & Sample 1 & Sample 2 \\
\hline & $\mathrm{N}(\%)$ & $\mathrm{N}(\%)$ \\
\hline \multicolumn{3}{|l|}{ Age } \\
\hline$<19$ & $18(4.6)$ & $37(6.7)$ \\
\hline $20-29$ & $269(69.3)$ & $423(76.2)$ \\
\hline $30-39$ & $69(17.8)$ & $76(13.7)$ \\
\hline $40-49$ & $18(4.6)$ & $13(2.3)$ \\
\hline $50-60$ & $14(3.6)$ & $6(1.1)$ \\
\hline \multicolumn{3}{|l|}{ Relationship } \\
\hline Yes & $206(53.1)$ & $398(71.7)$ \\
\hline No & $182(46.9)$ & $157(28.3)$ \\
\hline Heterosexual & $302(77.8)$ & $460(82.9)$ \\
\hline Bisexual & $78(20.1)$ & $75(13.5)$ \\
\hline Homosexual & $8(2.1)$ & $9(1.6)$ \\
\hline Other & - & $11(2.0)$ \\
\hline \multicolumn{3}{|c|}{ Frequency of sexual activity (last year) } \\
\hline At least weakly & $211(54.4)$ & $334(60.2)$ \\
\hline $1-2 \times$ per month & $94(24.2)$ & $143(25.8)$ \\
\hline$<$ Once per month & $54(13.9)$ & $53(9.6)$ \\
\hline No sexual intercourse & $29(7.5)$ & $25(4.5)$ \\
\hline \multicolumn{3}{|c|}{ Frequency of masturbation (last year) } \\
\hline At least weakly & $160(41.2)$ & $292(52.6)$ \\
\hline $1-2 \times$ per month & $108(27.8)$ & $163(29.4)$ \\
\hline$<$ Once per month & $80(20.6)$ & $72(13.0)$ \\
\hline Not at all & $40(10.3)$ & $28(5.1)$ \\
\hline
\end{tabular}

predictors for orgasm satisfaction, showing low explained variance in sample one $\left(\mathrm{F}(2)=3.50, \mathrm{p}=0.31, \mathrm{R}^{2}=0.02\right)$ and sample $2\left(\mathrm{~F}(2)=9.01, p=<0.01, \mathrm{R}^{2}=0.03\right)$. In a second step considering self-stimulation of the clitoris as good, important and exiting were added. The explained variance remained low in sample $1(\mathrm{~F}(5)=3.99, p<0.01$; $\left.\mathrm{R}^{2}=0.05\right)$ and sample $2\left(\mathrm{~F}(5)=4.99, p<0.01\right.$.; $\left.\mathrm{R}^{2}=0.04\right)$.

\section{Predictors of Sexual Satisfaction}

The multiple linear regression model to predict sexual satisfaction was able to resolve $21.6 \%$ of the variance in sample 1 and $16.5 \%$ of the variance in sample 2 (Table 3 ). Several variables could make a significant contribution to the explanation of variance. Orgasmic consistency by PVI without additional clitoral stimulation was found to predict sexual satisfaction in both samples. In sample 1, orgasm consistency due to stimulation by the partner's hand and to consider clitoral self-stimulation as exciting was also significant predictors. In sample 2, orgasm consistency due to PVI and direct clitoral stimulation and oral stimulation was significant predictors, whereas considering self-stimulation of the clitoris as important was a negative predictor. 


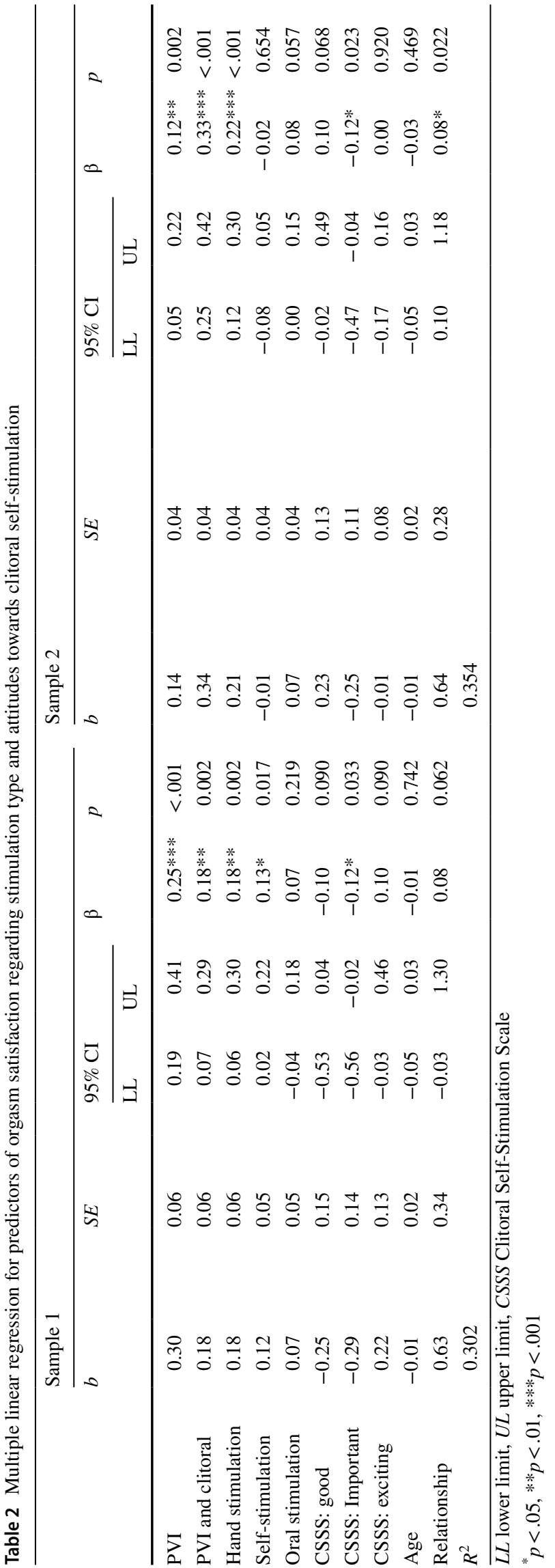

Also, for sexual satisfaction, hierarchical regressions were run, founding a small explained variance for age and relationship status for sample $1(\mathrm{~F}(2)=2.19$, $\left.p=0.11, \mathrm{R}^{2}=0.01\right)$ and sample $2(\mathrm{~F}(2)=11.23, p<0.01$, $\left.\mathrm{R}^{2}=0.04\right)$. Adding the items about clitoral self-stimulation rarely added explained variance in sample $1(\mathrm{~F}(5)=6.05$, $p<0.01$; $\left.\mathrm{R}^{2}=0.07\right)$ and sample $2(\mathrm{~F}(5)=6.70, p<0.01$, $\left.\mathrm{R}^{2}=0.06\right)$.

For a cross-validation of the regression model, the regression coefficients from the first sample were used to predict orgasm satisfaction and sexual satisfaction in the second sample. The predicted orgasm satisfaction was able to explain $29.5 \%$ of the variance of orgasm satisfaction in sample $2(\mathrm{~F}(1,553)=231.49, p<0.001)$. The predicted sexual satisfaction was able to explain $13.7 \%$ of the variance of the sexual satisfaction in sample $2(\mathrm{~F}(1$, $553)=87.68, p<0.001)$.

\section{Discussion}

The aim of this study was to investigate whether orgasmic consistency through different types of stimulation (PVI, PVI and direct clitoral stimulation, stimulation by the partner's hand, oral sex and self-stimulation of the clitoris during sex with a partner) influences orgasm satisfaction and sexual satisfaction. The role of affective and cognitive attitudes toward self-stimulation of the clitoris during sex with a partner was also included.

\section{Vaginal Penetration}

Orgasmic consistency through PVI without additional direct clitoral stimulation was the only factor that was a positive predictor of orgasm satisfaction as well as sexual satisfaction in both samples. This point is surprising, since many women even describe orgasm as more pleasurable when stimulated directly by the clitoris (Burri et al., 2009). Moreover, female orgasms are least likely to be caused by this type of stimulation. Although there is no biological difference between a vaginal and a clitoral orgasm, many women seem to desire orgasms through purely vaginal penetration. Likewise, these orgasms are especially strongly related to partnership satisfaction (Lehmann et al., 2004). Furthermore, orgasm is sometimes seen as a success criterion for good sex, which is why it is desired in order to help the partner feel competent (Salisbury \& Fisher, 2014). Sometimes, orgasms are faked to satisfy the partner as well as to finish the intercourse (Thomas et al., 2016). Although many women report achieving sexual satisfaction even without climax, there is sometimes a normative pressure to experience orgasms in order to feel normal and feminine (Nicolson \& Burr, 2003). This 
Table 3 Multiple linear regression for predictors of sexual satisfaction regarding stimulation type and attitudes towards clitoral self-stimulation

\begin{tabular}{|c|c|c|c|c|c|c|c|c|c|c|c|c|}
\hline & \multicolumn{6}{|c|}{ Sample 1} & \multicolumn{6}{|c|}{ Sample 2} \\
\hline & \multirow[t]{2}{*}{$b$} & \multirow[t]{2}{*}{$S E$} & \multicolumn{2}{|l|}{$95 \% \mathrm{CI}$} & \multirow[t]{2}{*}{$\beta$} & \multirow[t]{2}{*}{$p$} & \multirow[t]{2}{*}{$\bar{b}$} & \multirow[t]{2}{*}{$S E$} & \multicolumn{2}{|l|}{$95 \% \mathrm{CI}$} & \multirow[t]{2}{*}{$\beta$} & \multirow[t]{2}{*}{$p$} \\
\hline & & & $\mathrm{LL}$ & $\mathrm{UL}$ & & & & & $\mathrm{LL}$ & UL & & \\
\hline PVI & 0.77 & 0.16 & 0.46 & 1.08 & $0.24 * * *$ & $<.001$ & 0.41 & 0.13 & 0.17 & 0.67 & $0.14 * *$ & 0.001 \\
\hline PVI and clitoral & 0.22 & 0.16 & -0.08 & 0.53 & 0.08 & 0.154 & 0.26 & 0.13 & 0.01 & 0.51 & $0.10 *$ & 0.039 \\
\hline Hand stimulation & 0.52 & 0.17 & 0.19 & 0.85 & $0.19 * *$ & 0.002 & 0.24 & 0.13 & -0.01 & 0.49 & 0.10 & 0.064 \\
\hline Self-stimulation & 0.03 & 0.14 & -0.24 & 0.30 & 0.01 & 0.816 & 0.04 & 0.11 & -0.17 & 0.25 & 0.02 & 0.719 \\
\hline Oral stimulation & 0.09 & 0.15 & -0.21 & 0.39 & 0.03 & 0.566 & 0.27 & 0.12 & 0.05 & 0.50 & $0.12 *$ & 0.017 \\
\hline CSSS: good & 0.33 & 0.40 & -0.46 & 1.13 & 0.05 & 0.411 & 0.66 & 0.38 & -0.08 & 1.39 & 0.11 & 0.082 \\
\hline CSSS: important & -0.50 & 0.38 & -1.24 & 0.25 & -0.08 & 0.190 & -0.70 & 0.32 & -1.34 & -0.07 & $-0.13^{*}$ & 0.030 \\
\hline CSSS: exciting & 1.01 & 0.35 & 0.32 & 1.71 & $0.18 * *$ & 0.004 & 0.42 & 0.24 & -0.06 & 0.90 & 0.08 & 0.087 \\
\hline Age & -0.14 & 0.09 & -0.25 & -0.03 & $-0.11 *$ & 0.017 & -0.05 & 0.06 & -0.18 & 0.05 & -0.05 & 0.232 \\
\hline Relationship & 0.89 & 0.95 & -0.97 & 2.74 & 0.04 & 0.348 & 2.93 & 0.80 & 1.35 & 4.50 & $0.15 * * *$ & $<.001$ \\
\hline$R^{2}$ & 0.216 & & & & & & & & 0.165 & & & \\
\hline
\end{tabular}

$L L$ lower limit, $U L$ upper limit, CSSS Clitoral Self-Stimulation Scale

${ }^{*} p<.05 ; * * p<.01 ; * * * p<.001$

means the desire for an orgasm during vaginal penetration could arise from internal or external pressure (Chadwick et al., 2019). The image that women experience orgasms during sexual intercourse is spread in different media, whether it is magazines, novels, or pornographic videos (Cabrera \& Ménard, 2013; Lavie-Ajayi \& Joffe, 2009; Séguin et al., 2018). Therefore, it is not surprising that many people think that it is normal for women to reach orgasms during vaginal penetration (Ejder Apay et al., 2013). It seems to be evident that these heteronormative scripts about how sex should be are important in this matter. The problem is: If PVI is assumed to be the norm for sexuality, it can distract from other sexual needs (Willis et al., 2018). Also, valuations are found in the language we use, so that clitoral stimulation is often seen as foreplay. The term foreplay gives clitoral stimulation a minor role and implies that there is something else that is actually more important (Mahar et al., 2020). Additionally, the female orgasm achieved solely through penetration may be perceived as particularly important to protect the partner's feelings of masculinity and his ego (Muehlenhard \& Shippee, 2010). However, even education rectifying these sexual myths does not necessarily help to reduce these concerns (Bell \& McClelland, 2018). Emotions and norms about how sexuality should be experienced seem to be much more deeply rooted and need to be worked on more intensively to change.

\section{PVI with Direct Clitoral Stimulation}

If the clitoris is stimulated manually during intercourse, the orgasmic consistency increases clearly. Orgasm consistency through this type of stimulation was a predictor of orgasm satisfaction, but only in sample 2 also a predictor for the broader construct of sexual satisfaction. Nevertheless, it seems that simultaneous stimulation of the vagina and clitoris is particularly pleasurable for women. About $70 \%$ of women report that they use clitoral stimulation during penetration to make it more pleasurable (Hensel et al., 2021). Also neurobiologically, it can be shown that orgasms that result from stimulation of several regions also activate more orgasm-relevant neurons. Women describe these orgasms as more intense, more pleasurable, and more complex (Nemati \& Weitkamp, 2020). Nevertheless, orgasms through additional direct clitoral stimulation seem to be evaluated differently by some women. Phrasing of questions about women`s orgasm produces markedly different orgasm reports: While women experience orgasms during intercourse with direct clitoral stimulation in 51-60\% of cases, it is significantly less if you ask unspecifically with the phrasing "intercourse" (31-40\%). Asking specifically for intercourse without additional direct clitoral stimulation further reduces orgasmic consistency (21-30\%) (Shirazi et al., 2018). Accordingly, it seems to differ what women understand by orgasms during intercourse. It is possible that some women consider orgasms during intercourse with additional clitoral stimulation to be inferior and therefore do not report them. In addition, there is evidence that self-reported sexual satisfaction among women, and likewise among sexual minority men, relates to their partner's sexual satisfaction rather than to their own (McClelland, 2011). This phenomenon seems to be also influenced by heterosexual scripts, as women in same-sex relationships report enjoying orgasms through clitoral stimulation more than women in mixed-sex relationships (Blair et al., 2017). Moreover, some women find 
it awkward to ask their partner about clitoral stimulation (Salisbury \& Fisher, 2014) or even consider that their partner may be bored by clitoral stimulation (McCabe, 2005).

\section{Oral Sex}

Orgasmic consistency through oral sex was a positive predictor of sexual satisfaction in only one sample and no predictor of orgasm satisfaction. The ambiguous results could indicate that oral sex is perceived ambivalently by women. This may be related to conflicts with the body image and the genital self-image. While the woman is receiving oral sex, the vulva is exposed to the partner's view. This could be uncomfortable for certain women, because there are cultural norms indicating that the female genitals are unattractive (Braun \& Kitzinger, 2001). A positive attitude toward the female genitals is related to experiencing orgasms during cunnilingus and also to the ability to orgasm through this type of stimulation (Herbenick, 2009). In addition, sexual self-efficacy in achieving sexual pleasure also plays a role in whether or not women ask for and receive oral sex (Satinsky \& Jozkowski, 2015).

It is probably easier for women in long-term relationships to engage in oral sex. In long-term relationships, receiving oral sex is associated with sexual satisfaction (Frederick et al., 2017). Nevertheless, men enjoy oral sex more than women (Galinsky \& Sonenstein, 2011), and apparently not only in the receiving role: In mixed-sex relationships, men expressed the desire for more cunnilingus. However, women did not like to receive more oral sex (Blair et al., 2017).

\section{Stimulation by the Partner's Hand}

Orgasmic consistency by clitoral stimulation by the partner's hand was only a predictor for orgasm satisfaction in sample 2 and for sexual satisfaction in sample 1. This type of stimulation is most similar to female masturbation. The majority of women have one or two preferred masturbation techniques. The most common are up-and-down, as well as circular movements to stimulate the clitoris (Herbenick et al., 2018). More frequent masturbation is not necessarily related to more orgasms during sexual intercourse. There is a shift, that women masturbate at a younger age and more often than 20 years ago, but still have fewer orgasms during sexual intercourse (Kontula \& Miettinen, 2016). Maybe some women have to relearn how to enjoy different types of stimulation and experience orgasms through them. The stimulation of the clitoris by hand may be something normal and familiar and was therefore associated with increased satisfaction. A study investigating differences in the pleasure experienced during various sexual activities also found that women find receiving stimulation by the hand of their partner more pleasurable than men do (Pinkerton et al., 2003).

\section{Clitoral Self-Stimulation During Sex with a Partner}

Orgasm consistency through self-stimulation of the clitoris during sex with a partner was only a positive predictor of orgasm satisfaction in the first sample and no predictor for sexual satisfaction. All over, hierarchical regression approaches showed that there was little explained variance for attitudes towards clitoral self-stimulation with regard to orgasm and sexual satisfaction. This is surprising, as it might be assumed that women who are empowered to care for their own orgasms and sexual needs would report more satisfaction with sexuality. However, considering the self-stimulation of the clitoris during sex with a partner as good had no influence at all. The rating of self-stimulation as important even had a negative influence on orgasm satisfaction and in one sample also with sexual satisfaction. It could be assumed that women who have general problems reaching orgasm are more likely to perceive self-stimulation as important. However, it is equally reasonable to assume that these women experience clitoral orgasms; otherwise, this type of stimulation would probably not be perceived as important. Therefore, there is no generally valid explanation for a lower ability to orgasm that could cause the dissatisfaction. Maybe a mediating effect through sexual pressure to perform could be a cause of the negative relationship between considering self-stimulation of the clitoris as important and orgasm satisfaction. For example, the pressure to reach orgasm can cause orgasm problems, and concerns about orgasm difficulties can inhibit sexual functioning and may trigger a vicious circle (Sanders et al., 2008). Moreover, considering something as important is a cognitive factor and therefore maybe also a cognitive distraction. Cognitive distractions are known as negative factors for sexual satisfaction and sexual functioning (Adam et al., 2015; Cuntim \& Nobre, 2011). Another explanation for the negative association could be that some women need a very specific stimulation of the clitoris to reach orgasm and therefore self-stimulation is considered as important. When the body becomes immobile during stimulation, this is associated with fewer orgasms (BischofCampbell et al., 2019). Some women also find it embarrassing to stimulate their clitoris during sex and are worried that their partner might feel incompetent as a consequence (Salisbury \& Fisher, 2014). In addition, self-stimulation is the sexual activity that is most rarely practiced during sexual encounters, although it increases during longer relationships (Smith et al., 2012).

On the other hand, considering the stimulation of the clitoris as exciting was a positive predictor of sexual satisfaction in the first sample. It was no predictor of orgasm satisfaction. In this case, the emotional instead of the cognitive level is addressed. A positive effect on clitoral self-stimulation therefore seems to be more likely to be positive for sexual satisfaction.

The results indicate that a differentiated consideration of the types of stimulation during sex with a partner is important, with special emphasis on the motives and deeper assumptions 
about sexuality, like internalized heteronormative scripts. If considering the clitoral self-stimulation during sex with a partner as important is no positive predictor for sexual satisfaction or orgasm satisfaction, the question arises why this type of stimulation is considered as important at all. If it happens for one's own pleasure, why does not it increase satisfaction? Also, if it does not happen for one's own pleasure, is it again just about the man's satisfaction or for a normative pressure to reach orgasm? Chasing an orgasm may distract from pleasure and cause pressure to perform. Maybe self-stimulation is also used to appear sexy and confident. Also, in heterosexual encounters, the male desire to observe a woman masturbating could be a possible motive (Fahs \& Frank, 2014).

\section{Limitations and Strengths}

A limiting factor is that both samples were acquired online, consisting mainly of young, heterosexual, and well-educated women. Also, because the survey was spread through e-mail lists and internet forums to interested persons, it is likely that the sample is biased towards individuals who are open minded toward the topic of sexuality. Still, we found concerns about clitoral self-stimulation and great variations in given responses. Nevertheless, these results should be interpreted with caution and cannot be applied to the general population. Another limitation is the cross-sectional nature of the data. Therefore, assertions about causality cannot be derived.

Although the FOS and the CSSS are still relatively unknown instruments, they offer an unusual and unique view on female sexuality. By asking detailed questions about orgasmic consistency, orgasm satisfaction and attitudes toward self-stimulation of the clitoris, we expect it to help to gain a deeper understanding of this. Since this is an exploratory study, a replication in a second, independent sample was performed to methodically support the results. The fact that most of the results could be found in both large samples should be emphasized as strength of the study. The cross-validation of the regression model from the first sample in the second sample showed an explained variance in the medium to good range. There were shifts in the significant predictors, but the differences were mostly small, and the direction of the effects remained the same.

\section{Future Directions and Conclusions}

The results indicate that some young women are still strongly driven by the desire to experience orgasms through vaginal penetration and that clitoral stimulation can cause ambivalent feelings.

The exact roles of heteronormative scripts and sexual performance pressure would be interesting to investigate in further studies. It also remains an open question whether similar results occur in older women or whether it could be expected that a more pleasure-oriented sexuality would develop in later life.
Depending on the types of stimulation used, women's orgasms can be given different subjective meanings. There is no simple connection that all orgasms lead to sexual satisfaction; rather, there seem to be complex and sometimes ambivalent relationships. The findings indicate that even behaviors that might initially be associated with empowerment, such as selfstimulation during sex with a partner, may be related to a variety of mechanisms. An empowered woman during sex may also trigger discomfort in the man, making him appear dissatisfied and thus minimizing the woman's satisfaction. Investigating such dyadic aspects would also be of high relevance. Overall, the work reveals many indications of the extent to which heteronormative sexual scripts influence sexuality. This shows the importance of challenging and discussing these assumptions. Especially for young people who are just discovering their sexuality, such rigid ideas about the process of sexuality could be intimidating, making it difficult to explore personal needs. Also, the samples in this study consisted mainly of young and highly educated women; this group may be vulnerable to this. It is also possible that well-educated young women are particularly engaged in self-optimization, which may encourage sexual pressure to perform. Moreover, there is little education about sexual functioning at school (Cormier \& O'Sullivan, 2018), which could be a possible reason for this pressure. It is especially important for adolescents to discover their own bodies: Regular masturbation during this time facilitates experiencing orgasms during sexual intercourse (Carvalheira \& Leal, 2013). Therefore, sex-positive education in school is important, including pleasure, clitoris stimulation, and the natural differences between female and male sexuality (Koepsel, 2016). Historically, the clitoris as an organ was long neglected and tabooed (Charlier et al., 2020). Against this background, it is not surprising that the clitoris still triggers ambivalent feelings today. Without public statements against such assumptions, sex education is largely left to the media, which convey the image of sexually submissive women with a lack of sexual autonomy (Sanchez et al., 2006). Benevolent sexism is also linked to orgasm frequency, because women scoring high on implicit sexism scales are less willing to speak about sexual needs (Harris et al., 2016). Difficulties in talking about clitoral stimulation in a couple are related to female anorgasmia (Herbenick, 2009). In this context, it is important to promote female sexual self-efficacy. If women feel confident that they can enjoy sex, they are more likely to talk to their partner about their sexual desires (Satinsky \& Jozkowski, 2015).

Sexuality which is pleasure-oriented instead of only goal-oriented and orgasm-focused is especially intense and valuable. For this, a mindful contact with oneself and the partner is important (Nemati \& Weitkamp, 2020). Questioning one's own sexual scripts can be an important task in this context. Naming them in a non-judgmental way and assessing whether or not they are helpful for a satisfying sexuality could have a positive influence. 
Therefore, sexual education and counseling should help people to identify sexual thoughts and activities, which are the results of normative pressures and to encourage people to connect more with their inner needs and feelings about sexuality.

Funding Open Access funding enabled and organized by Projekt DEAL.

\section{Declarations}

Ethics Approval The studies received ethical approval from the Ethics Committee of the Jena University Hospital, Germany (4837-06/16 and 1859-2020).

Informed Consent Informed consent was obtained from all individual participants included in the studies.

Conflict of Interest The authors declare no competing interests.

Open Access This article is licensed under a Creative Commons Attribution 4.0 International License, which permits use, sharing, adaptation, distribution and reproduction in any medium or format, as long as you give appropriate credit to the original author(s) and the source, provide a link to the Creative Commons licence, and indicate if changes were made. The images or other third party material in this article are included in the article's Creative Commons licence, unless indicated otherwise in a credit line to the material. If material is not included in the article's Creative Commons licence and your intended use is not permitted by statutory regulation or exceeds the permitted use, you will need to obtain permission directly from the copyright holder. To view a copy of this licence, visit http://creativecommons.org/licenses/by/4.0/.

\section{References}

Adam, F., Géonet, M., Day, J., \& De Sutter, P. (2015). Mindfulness skills are associated with female orgasm? Sexual and Relationship Therapy, 30(2), 256-267. https://doi.org/10.1080/14681994. 2014.986085

Andrejek, N., \& Fetner, T. (2019). The gender gap in orgasms: Survey data from a mid-sized Canadian City. International Journal of Sexual Health, 31(1), 26-35. https://doi.org/10.1080/19317611. 2018.1563014

Bell, S. N., \& McClelland, S. I. (2018). When, if, and how: Young women contend with orgasmic absence. The Journal of Sex Research, 55(6), 679-691. https://doi.org/10.1080/00224499. 2017.1384443

Bentler, P. M., \& Peeler, W. H. (1979). Models of female orgasm. Archives of Sexual Behavior, 8(5), 405-423. https://doi.org/10.1007/BF01541197

Bischof-Campbell, A., Hilpert, P., Burri, A., \& Bischof, K. (2019). Body movement is associated with orgasm during vaginal intercourse in women. The Journal of Sex Research, 56(3), 356-366. https://doi.org/10.1080/00224499.2018.1531367

Blair, K. L., Cappell, J., \& Pukall, C. F. (2017). Not all orgasms were created equal: Differences in frequency and satisfaction of orgasm experiences by sexual activity in same-sex versus mixed-sex relationships. The Journal of Sex Research, 55(6), 719-733. https:// doi.org/10.1080/00224499.2017.1303437

Blechner, M. J. (2017). The clitoris: Anatomical and psychological issues. Studies in Gender and Sexuality, 18(3), 190-200. https:// doi.org/10.1080/15240657.2017.1349509
Bowman, C. P. (2014). Women's masturbation: Experiences of sexual empowerment in a primarily sex-positive sample. Psychology of Women Quarterly, 38(3), 363-378. https://doi.org/10.1177/ 0361684313514855

Braun, V., \& Kitzinger, C. (2001). The perfectible vagina: Size matters. Culture, Health \& Sexuality, 3(3), 263-277. https://doi.org/ 10.1080/13691050152484704

Burri, A. V., Cherkas, L., \& Spector, T. D. (2009). Genetic and Environmental Influences on Self-Reported G-Spots in Women: A Twin Study. https://doi.org/10.1111/j.1743-6109.2009.01671.x

Cabrera, C., \& Ménard, A. D. (2013). "She exploded into a million pieces": A qualitative and quantitative analysis of orgasms in contemporary romance novels. Sexuality \& Culture, 17(2), 193-212. https://doi.org/10.1007/s12119-012-9147-0

Carvalheira, A., \& Leal, I. (2013). Masturbation among women: Associated factors and sexual response in a Portuguese community sample. Journal of Sex \& Marital Therapy, 39(4), 347-367. https://doi.org/10.1080/0092623X.2011.628440

Chadwick, S. B., Francisco, M., \& van Anders, S. M. (2019). When orgasms do not equal pleasure: Accounts of "bad" orgasm experiences during consensual sexual encounters. Archives of Sexual Behavior, 48(8), 2435-2459. https://doi.org/10.1007/ s10508-019-01527-7

Charlier, P., Deo, S., \& Perciaccante, A. (2020). A brief history of the clitoris. Archives of Sexual Behavior, 49(1), 47-48. https://doi. org/10.1007/s10508-020-01638-6

Cormier, L. A., \& O’Sullivan, L. F. (2018). Anti-climactic: Investigating how late adolescents perceive and deal with orgasm difficulty in the context of their intimate relationships. The Canadian Journal of Human Sexuality, 27(2), 111-122. https://doi.org/10.3138/ cjhs.2018-001

Cuntim, M., \& Nobre, P. (2011). The role of cognitive distraction on female orgasm. Sexologies, 20(4), 212-214. https://doi.org/10. 1016/j.sexol.2011.08.001

de Sutter, P., Day, J., \& Adam, F. (2014). Who are the orgasmic women? Exploratory study among a community sample of French-speaking women. Sexologies, 23(3), e51-e57. https://doi. org/10.1016/j.sexol.2014.05.003

Dunn, K. M., Cherkas, L. F., \& Spector, T. D. (2005). Genetic influences on variation in female orgasmic function: A twin study. Biology Letters, 1(3), 260-263. https://doi.org/10.1098/rsbl.2005.0308

Ejder Apay, S., Nagorska, M., Balcı Akpınar, R., Sis Çelik, A., \& Binkowska-Bury, M. (2013). Student comparison of sexual myths: Two-country case. Sexuality and Disability, 31(3), 249-262. https:// doi.org/10.1007/s11195-013-9301-0

Fahs, B., \& Frank, E. (2014). Notes from the back room: Gender, power, and (in) visibility in women's experiences of masturbation. The Journal of Sex Research, 51(3), 241-252.

Frederick, D. A., Lever, J., Gillespie, B. J., \& Garcia, J. R. (2017). What keeps passion alive? Sexual satisfaction is associated with sexual communication, mood setting, sexual variety, oral sex, orgasm, and sex frequency in a national US study. The Journal of Sex Research, 54(2), 186-201. https://doi.org/10.1080/00224499.2015.1137854

Galinsky, A. M., \& Sonenstein, F. L. (2011). The association between developmental assets and sexual enjoyment among emerging adults. Journal of Adolescent Health, 48(6), 610615. https://doi.org/10.1016/j.jadohealth.2010.09.008

Graham, C. A. (2010). The DSM diagnostic criteria for female orgasmic disorder. Archives of Sexual Behavior, 39(2), 256-270. https://doi.org/10.1007/s10508-009-9542-2

Harris, E. A., Hornsey, M. J., \& Barlow, F. K. (2016). On the link between benevolent sexism and orgasm frequency in heterosexual women. Archives of Sexual Behavior, 45(8), 1923-1931. https:// doi.org/10.1007/s10508-016-0780-9

Hensel, D. J., von Hippel, C. D., Lapage, C. C., \& Perkins, R. H. (2021). Women's techniques for making vaginal penetration 
more pleasurable: Results from a nationally representative study of adult women in the United States. PLoS One, 16(4), e0249242. https://doi.org/10.3886/E128421V2

Herbenick, D., Fu, T. -C., Arter, J., Sanders, S. A., \& Dodge, B. (2018). Women's experiences with genital touching, sexual pleasure, and orgasm: Results from a U.S. probability sample of women ages 18 to 94. Journal of Sex \& Marital Therapy, 44(2), 201-212. https:// doi.org/10.1080/0092623X.2017.1346530

Herbenick, D. L. (2009). The development and validation of a scale to measure attitudes toward women's genitals. International Journal of Sexual Health, 21(3), 153-166. https://doi.org/10.1080/ 19317610903149692

Hoy, M., Strauß, B., Kröger, C., \& Brenk-Franz, K. (2019). Evaluation of the German short version of the "New Sexual Satisfaction Scale" (NSSS-SD) in a representative sample. Psychotherapie Psychosomatik Medizinische Psychologie, 69(03/04), 129-135. https://doi.org/10.1055/a-0620-0002

Jackson, M. (1984). Sex research and the construction of sexuality: A tool of male supremacy? Women's Studies International Forum, 7(1), 43-51. https://doi.org/10.1016/0277-5395(84)90083-9

Koepsel, E. R. (2016). The power in pleasure: Practical implementation of pleasure in sex education classrooms. American Journal of Sexuality Education, 11(3), 205-265. https://doi.org/10.1080/ 15546128.2016.1209451

Kontula, O., \& Miettinen, A. (2016). Determinants of female sexual orgasms. Socioaffective Neuroscience \& Psychology, 6(1), 31624. https://doi.org/10.3402/snp.v6.31624

Lavie-Ajayi, M., \& Joffe, H. (2009). Social representations of female orgasm Journal of Health Psychology, 14(1), 98-107. https://doi. org/10.1177/1359105308097950

Lehmann, A., Rosemeier, H. -P., \& Grusser-Sinopoli, S. (2004). Weibliches Orgasmuserleben: Vaginal-klitoral? Sexuologie, 10(4), 128-133.

Leiner, D. J. (2014). SoSci survey (version 2.5. 00-i)[computer software].

Leiner, D. J. (2019). Too Fast, too Straight, too Weird: Non-Reactive Indicators for Meaningless Data in Internet Surveys. Survey Research Methods, 13(3), 229-248. https://doi.org/10.18148/ srm/2019.v13i3.7403

Leonhardt, N. D., Willoughby, B. J., Busby, D. M., Yorgason, J. B., \& Holmes, E. K. (2018). The significance of the female orgasm: A nationally representative, dyadic study of newlyweds' orgasm experience. The journal of sexual medicine, 15(8), 1140-1148.

Mah, K., \& Binik, Y. M. (2001). The nature of human orgasm: a critical review of major trends. Clinical Psychology Review, 21(6), 823-856. https://doi.org/10.1016/S0272-7358(00)00069-6

Mah, K., \& Binik, Y. M. (2005). Are orgasms in the mind or the body? Psychosocial versus physiological correlates of orgasmic pleasure and satisfaction. Journal of Sex \& Marital Therapy, 31(3), 187-200. https://doi.org/10.1080/00926230590513401

Mahar, E. A., Mintz, L. B., \& Akers, B. M. (2020). Orgasm equality: Scientific findings and societal implications. Current Sexual Health Reports, 12(1), 24-32. https://doi.org/10.1007/ s11930-020-00237-9

Matthias, R. E., Lubben, J. E., Atchison, K. A., Schweitzer, S. O. (1997). Sexual Activity and Satisfaction Among Very Old Adults: Results From a Community-Dwelling Medicare Population Survey. The Gerontologist 37(1) 6-14 https://doi.org/10.1093/geront/37.1.6

McCabe, M. P. (2005). The role of performance anxiety in the development and maintenance of sexual dysfunction in men and women. International Journal of Stress Management, 12(4), 379. https://doi.org/10. 1037/1072-5245.12.4.379

McClelland, S. I. (2011). Who is the "self" in self reports of sexual satisfaction? Research and Policy Implications. Sexuality Research and Social Policy, 8(4), 304. https://doi.org/10.1007/ s13178-011-0067-9

McIntyre-Smith, A., \& Fisher, W. A. (2011a). Clitoral Self-Stimulation Scale. In T. D. Fisher, C. M. Davis, W. L. Yarber, \& S. L. Davis
(Eds.), Handbook of Sexuality-Related Measures (Third ed.). Routledge.

McIntyre-Smith, A., \& Fisher, W. A. (2011b). Female Orgasm Scale. In T. D. Fisher, C. M. Davis, W. L. Yarber, \& S. L. Davis (Eds.), Handbook of Sexuality-Related Measures (Third ed.). Routledge.

McClelland, S. I. (2014). "What do you mean when you say that you are sexually satisfied?" A mixed methods study. Feminism \& Psychology 24(1) 74-96 https://doi.org/10.1177/0959353513508392

Muehlenhard, C. L., \& Shippee, S. K. (2010). Men's and women's reports of pretending orgasm. Journal of Sex Research, 47(6), 552-567. https://doi.org/10.1080/00224490903171794

Nemati, A. L. J., \& Weitkamp, K. (2020). The female orgasmic state and the different dimensions of the female sexual experience: Lessons learned from expert interviews. Sexual and Relationship Therapy, 1-24. https://doi.org/10.1080/14681994.2020.1789089

Nicolson, P., \& Burr, J. (2003). What is 'normal' about women's (hetero)sexual desire and orgasm?: A report of an in-depth interview study. Social Science \& Medicine, 57(9), 1735-1745. https://doi. org/10.1016/s0277-9536(03)00012-1

O'Connell, H. E., Eizenberg, N., Rahman, M., \& Cleeve, J. (2008) The Anatomy of the Distal Vagina: Towards Unity. The Journal of Sexual Medicine 5(8) 1883-1891 https://doi.org/10.1111/j.17436109.2008.00875.x

Philippsohn, S., \& Hartmann, U. (2009). Determinants of sexual satisfaction in a sample of German women. The Journal of Sexual Medicine, 6(4), 1001-1010. https://doi.org/10.1111/j.1743-6109. 2008.00989.x

Philippsohn, S., Heiser, K., \& Hartmann, U. (2003). Sexual satisfaction and sexual myths among women: Results of a survey on the determinants of sexual satisfaction. Sexuologie: Zeitschrift für Sexualmedizin, Sexualtherapie und Sexualwissenschaft, 9(4), 148-154.

Pinkerton, S., Cecil, H., Bogart, L., \& Abramson, P. (2003). The pleasures of sex: An empirical investigation. Cognition and Emotion, 17(2), 341-353. https://doi.org/10.1080/02699930302291

Prause, N., Kuang, L., Lee, P., \& Miller, G. (2016). Clitorally stimulated orgasms are associated with better control of sexual desire, and not associated with depression or anxiety, compared with vaginally stimulated orgasms. The Journal of Sexual Medicine, 13(11), 1676-1685. https://doi.org/10.1016/j.jsxm.2016.08.014

Rowland, D. L., \& Kolba, T. N. (2016). Understanding orgasmic difficulty in women. The Journal of Sexual Medicine, 13(8), 1246-1254. https://doi.org/10.1016/j.jsxm.2016.05.014

Salisbury, C. M., \& Fisher, W. A. (2014). "Did you come?” A qualitative exploration of gender differences in beliefs, experiences, and concerns regarding female orgasm occurrence during heterosexual sexual interactions. Journal of Sex Research, 51(6), 616-631. https://doi.org/10.1080/00224499.2013.838934

Sanchez, D. T., Kiefer, A. K., \& Ybarra, O. (2006). Sexual submissiveness in women: Costs for sexual autonomy and arousal. Personality and Social Psychology Bulletin, 32(4), 512-524. https://doi. org/10.1177/0146167205282154

Sanders, S. A., Graham, C. A., \& Milhausen, R. R. (2008). Predicting sexual problems in women: The relevance of sexual excitation and sexual inhibition. Archives of Sexual Behavior, 37(2), 241-251. https://doi.org/10.1007/s10508-007-9235-7

Satinsky, S., \& Jozkowski, K. N. (2015). Female sexual subjectivity and verbal consent to receiving oral sex. Journal of Sex \& Marital Therapy, 41(4), 413-426. https://doi.org/10.1080/0092623X.2014.918065

Séguin, L. J., \& Blais, M. (2019). Pleasure is just the tip of the iceberg: Social representations, personal beliefs, and attributed meanings to partnered orgasm. The Canadian Journal of Human Sexuality, 28(3), 328-342. https://doi.org/10.3138/cjhs.2019-0027

Séguin, L. J., Rodrigue, C., \& Lavigne, J. (2018). Consuming ecstasy: Representations of male and female orgasm in mainstream pornography. The Journal of Sex Research, 55(3), 348-356. https://doi.org/ 10.1080/00224499.2017.1332152 
Shirazi, T., Renfro, K. J., Lloyd, E., \& Wallen, K. (2018). Women's experience of orgasm during intercourse: Question semantics affect women's reports and men's estimates of orgasm occurrence. Archives of Sexual Behavior, 47(3), 605-613. https:// doi.org/10.1007/s10508-017-1102-6

Smith, A. M., Patrick, K., Heywood, W., Pitts, M. K., Richters, J., Shelley, J. M., Simpson, J. M., \& Ryall, R. (2012). Sexual practices and the duration of last heterosexual encounter: Findings from the australian longitudinal study of health and relationships. Journal of Sex Research, 49(5), 487-494. https://doi.org/10.1080/00224499.2011. 598247

Stulhofer, A., Busko, V., \& Brouillard, P. (2010). Development and bicultural validation of the New Sexual Satisfaction Scale. The Journal of Sex Research, 47(4), 257-268. https://doi.org/10.1080/ 00224490903100561
Tavares, I. M., Laan, E. T. M., \& Nobre, P. J. (2017). Cognitive-affective dimensions of female orgasm: The role of automatic thoughts and affect during sexual activity. The Journal of Sexual Medicine, 14(6), 818-828. https://doi.org/10.1016/j.jsxm.2017.04.004

Thomas, E. J., Stelzl, M., \& Lafrance, M. N. (2016). Faking to finish: Women's accounts of feigning sexual pleasure to end unwanted sex. Sexualities, 20(3), 281-301. https://doi.org/10. $1177 / 1363460716649338$

Willis, M., Jozkowski, K. N., Lo, W. -J., \& Sanders, S. A. (2018). Are women's orgasms hindered by phallocentric imperatives? Archives of Sexual Behavior, 47(6), 1565-1576. https://doi.org/10.1080/ 14681994.2013.807912.

Publisher's Note Springer Nature remains neutral with regard to jurisdictional claims in published maps and institutional affiliations. 